\title{
Connection Failure: Systemic Disadvantages Facing the LGBTQ+ Community in Therapy and how to Address them
}

\section{Erin Roach \\ University of Ottawa}

This paper examines the experiences of members of the LGBTQ+ community in accessing mental health care in Ottawa, Canada, both positive and negative, and what might be done to improve outcomes. The paper includes a literature review of empirical studies and theoretical works about conducting therapy with LGBTQ+ clients, as well as the results of a pilot study conducted by the researcher to examine in depth the experience of a small sample of LGBTQ+ clients in Ottawa $(\mathrm{N}=4)$. Through semi-structured interviews, the researcher found that three out of four participants had experienced some dissatisfaction with how their identity was addressed in therapy, and as a result their overall well-being had suffered. This implies that therapists could be doing more to connect with their LGBTQ+ clients, potentially through better educating themselves on the issues affecting the community, as recommended by the participants. Increasing therapist knowledge would likely improve mental health outcomes for LGBTQ+ clients.

Keywords: LGBTQ+, LGBT, queer, counselling, psychology, therapy

Cet article porte sur les expériences à la fois positives et négatives vécues par des membres de la communauté LGBTQ + en matière d'accès aux soins de santé mentale à Ottawa, Canada, ainsi que ce qui pourrait être fait pour améliorer ces expériences. L'article comprend une analyse documentaire d'études empiriques et d'ouvrages théoriques portant sur la thérapie avec des clients LGBTQ +, ainsi que les résultats d'une étude pilote menée par la chercheure afin d'examiner en profondeur l'expérience d'un échantillon réduit de clients LGBTQ + à Ottawa $(\mathrm{N}=4)$. Grâce à des entretiens semi-structurés, la chercheure a constaté que trois participants sur quatre étaient mécontentement face au traitement réservé à leur identité durant la thérapie; leur bien-être général en a souffert. Cela signifie que les thérapeutes pourraient faire mieux en matière de communication avec leurs clients LGBTQ +, en s'informant davantage sur les problèmes qui touchent cette communauté, telle que le recommandent les participants. Cette connaissance accrue chez le thérapeute pourrait contribuer à de meilleurs résultats pour les clients LGBTQ + en matière de santé mentale.

Mots-clés : $L G B T Q+, L G B T$, queer, counseling, psychologie, thérapie 


\section{ACTES DU SJPD-JPDS PROCEEDINGS, 2018, VOL. 2}

Therapy, like any kind of health care, is meant to help those who (can) access it. Unfortunately, most models of therapy were created within white, Western, heteropatriarchal societies and therefore have a history of struggling to address the needs of individuals who have been disadvantaged by systems of power, such as misogyny, racism, or homophobia (Cochran, Sullivan, \& Mays, 2003).

This research focused on one minority group in particular, that of the Lesbian, Gay, Bisexual, Transgender, and Queer (LGBTQ+) community. Same-sex attraction was classified as a mental disorder from the first edition of the Diagnostic and Statistics Manual, published in 1952, until the fourth edition (DSM-IV-TR, 2000). Furthermore, gender dysphoria, defined as a strong desire to be a gender other than the one assigned at birth, is still listed as a mental disorder in the DSM-5 (2013).

Research indicates that LGBTQ+ people seek therapy at a higher rate than heterosexual, cisgender ${ }^{3}$ people (Cochran et al., 2003). Despite this, many recent graduates from psychology programs in the United States report feeling unprepared to work with LGBTQ+ clients (Sherry, Whilde, \& Patton, 2005). Furthermore, many LGBTQ+ clients report "considerable discrimination and hostility" from their therapists (Shelton \& DelgadoRomero, 2011, p. 210).

The therapeutic relationship is impacted by any potential biases held by the therapist, whether intentional or not. North American society is heteronormative and cisnormative, meaning that people are expected to be heterosexual and to identify with the gender they were assigned at birth, and that those who fall outside of these norms often face discrimination and prejudice (Ginicola, Smith, \& Filmore, 2017). Anyone within such a society can hold heteronormative and cisnormative bias, even unconsciously; therefore, even a therapist with the best of intentions can damage the therapeutic relationship due to underlying prejudice.

The objective of the present research was to explore to what extent the experiences of LGBTQ+ clients in psychotherapy are positive and/or negative, and what contributes to those experiences (e.g., therapist behaviour, techniques, therapeutic approaches). First, the researcher examined some of the recent empirical studies and theoretical papers on the topic, summarized below. Then, the researcher conducted a pilot study with members of the LGBTQ+ community who had attended therapy. The goal of the research was to deepen the

\footnotetext{
3 "Cisgender" is a term describing someone who identifies with the gender they were assigned at birth - i.e. the opposite of transgender (Ginicola, Smith, \& Filmore, 2017).
} 


\section{ACTES DU SJPD-JPDS PROCEEDINGS, 2018, VOL. 2}

understanding of where problems may exist for LGBTQ+ clients in order to use this information to better prepare therapists to work with members of the community, and therefore, improve mental health outcomes for them.

\section{Literature Synthesis}

An influential study for the formation of the present research, conducted by O'Shaughnessy and Spokane (2013), discussed the limitations of affirmative therapy. Affirmative therapy is the only LGBT-specific approach and refers more to the act of applying an appreciation of queer struggles to the therapy than a therapeutic model in itself. The intraining participants had to present their therapeutic conceptualizations (i.e., theory and plan) of a series of clinical vignettes involving queer clients (e.g., a gay man adjusting to a new job) which they were then rated on out of a score of 25 . Then the participants rated their own competence on working with LGBTQ+ clients. Researchers found that there was a significant discrepancy between therapists' self-assessment scales and their scores on the clinical vignettes (participants had a mean score of 4 points out of a possible 25 on the vignettes, but had scored themselves above average on the assessment scales). This data indicates that many therapists-in-training may see themselves as more competent in working with LGBTQ+ clients than they really are. Clearly, there need to be other metrics by which to assess a therapeutic relationship beyond therapist self-assessment, for example, by talking to clients. This finding was partially reinforced by Johnson and Federman (2014), who found that recent psychology graduates feel competent when it comes to working with the LGBT population, but have not received any specific training or experience with that population. Furthermore, Bidell and Whitman (2013) assessed scales and inventories meant to explore competency with LGB clients, and, while they found the scales to be valid and reliable, they also suggested that educators should develop opportunities for students to work with LGB populations directly. Bidell (2017) also developed his own self-assessment scale that includes transgender populations, though it comes with all the same limitations as other therapist self-assessment scales discussed above.

The other study that was foundational to the present research was conducted by Shelton and Delgado-Romero (2011), which focused more on clients. This study emphasized microaggressions in psychotherapy, and how they deter LGBQ clients from seeking mental health care. Micro-aggressions are looks, gestures, tones, and word choices that communicate prejudice, often unintentionally, like a certain tone of voice when saying "gay", for example. The researchers looked at 16 people who identified as LGBQ in the United States who were split into two focus groups and asked questions about their experiences with 


\section{ACTES DU SJPD-JPDS PROCEEDINGS, 2018, VOL. 2}

therapists. Seven themes emerged in the discussions: over-emphasis of sexual orientation, avoidance of sexual orientation, attempts to over-identify with the client, making stereotypical assumptions about the client, expression of heteronormative bias, assumption that queerness was inherently unhealthy, and warnings about dangers of identifying as LGBQ. The participants reported, as a result, feelings of discomfort and manipulation, a loss of faith in the profession, and a decreased likelihood of seeking therapy again. Spengler, Miller, and Spengler (2016) also looked at microaggressions towards sexual minority clients and suggested strategies for how to create a more affirmative therapeutic environment. For example, they suggested that therapists could do this through guarding against language errors and not making assumptions about identity.

O'Shaughnessy and Speir (2018) conducted a systematic review of 49 empirical studies on effective therapy with LGBQ clients. They found that there had been significant growth in the field in recent years, but that there is still a lack of clarity about what exactly constitutes affirmative therapy, as well as no established way to assess client outcomes. The researcher sampled available literature, both empirical studies and theoretical papers, to gain a fuller understanding into the topic of counselling LGBTQ+ clients. The first of these was conducted by Chui, McGann, Ziemer, Hoffman, and Stahl (2017) and explored the importance of supervisors in the counselling setting in the United States. They examined the role of supervision of recent psychotherapy graduates by more seasoned therapists in working with LGQ clients and other minorities. Chui and colleagues (2017) found that having a strong supervisor relationship improved the therapists' perceived relationships with all clients, including sexual minorities. This could indicate that having someone else to turn to for advice is beneficial in getting past any unconscious biases; however, the study did not survey clients to see if they also experienced an improvement in the relationship.

Alessi, Dillon, and Kim $(2015 ; 2016)$ conducted two empirical studies on the topic of LGBTQ+ counselling. The first study (2015) found that more affirmative attitudes in the counsellor contribute to more affirmative practice. They suggested that students need to be given opportunities to counsel queer clients and that training programs should focus on improving attitudes towards the LGBTQ+ community. The second study (2016) expanded on the earlier research, suggesting that aspiring therapists should be encouraged to explore their own sexual identity development and how it may affect their work with LGBTQ+ clients. Ebersole, Dillon, and Eklund (2018) found that therapists have greater knowledge and skills about lesbian and gay clients than they do about bisexual clients, indicating that a general LGB competency may not exist. 


\section{ACTES DU SJPD-JPDS PROCEEDINGS, 2018, VOL. 2}

Diamond and Shpigel (2014) explored whether or not attachment-based family therapy could help queer young adults reconnect with their parents. The researchers attempted to repair the attachment bond that had been broken by strife over the person's queer identity, while also promoting their autonomy and competence. This method was very successful in some cases, moderately successful in others, and failed in a few other cases, seemingly mediated by individual differences between participants.

Steelman (2016) used another approach, narrative therapy, which is believed to be particularly useful with minority clients because it considers cultural contributions to a problem, such as systemic inequality and discrimination. Steelman's case study used a narrative technique called externalization, which separates a person from their problem, to help a gay adolescent decouple the cultural meaning of "being gay" from the adolescent's own meaning of being gay, thereby giving him control over the label and his own story.

The other type of literature surveyed for the present study were theoretical papers, detailing potential avenues of interest for therapists working with LGBTQ+ clients. Addison and Coolhart (2015) emphasized the use of intersectionality to address the complex identities present in therapy. Intersectionality, which comes from feminist theory, is a way of considering the different axes of power and oppression, such as sexism, racism, or homophobia. These researchers also focused on minimizing the power difference between therapist and client.

Hicks's (2010) article discussed counselling people who belong to more than one marginalized group, known as a double minority. A therapist must be mindful of the ways in which each identity plays a role in the client's life. For example, a physically disabled gay man may experience homophobia in the same way an able-bodied gay man would, but he may also experience ableism from both society at large and from the queer community (e.g. a gay bar in a basement with no elevator).

The gathered literature also contained two collections of articles about counselling LGBTQ+ clients, one edited by Dworkin and Pope (2015) and one edited by Ginicola and colleagues (2017). Both have a multicultural, affirmative approach to the issue of how to counsel LGBTQ+ clients, meaning that, instead of suggesting specific techniques or theories, they are comprised of articles detailing how different groups within the community define themselves and information that might be useful to therapists who are working with clients who belong to those groups. These articles include information ranging from lifestyle concerns to cultural issues; for example, how bisexual people often face discrimination from 


\section{ACTES DU SJPD-JPDS PROCEEDINGS, 2018, VOL. 2}

both mainstream society and gay men and lesbians, or the history of non-binary genders in some Indigenous cultures.

McDowell, Emerick, and Garcia (2014) identified that the field of family therapy has not made any attempt to address an increase in families with LGBTQ+ members. They suggest that models of family therapy are still bound up in heterosexist norms (e.g. marriage to a different-gender partner, having children), and that this is problematic when it comes to addressing LGBTQ+ clients whose lives may look much different. The researchers suggested that therapists should engage in a dialogue with both colleagues and clients that challenge the heteronormative constructs of family in order to better address the needs of all families and all clients.

Finally, Hodges (2011) wrote that psychoanalysis, while an older theory, can still be relevant, and is particularly useful when working with queer clients because it deals with understanding and resisting power. Instead of breaking down the power difference in the therapist-client relationship, which other approaches might try, psychoanalysis makes use of the therapist's power to authorize the client to embrace and normalize their own experiences.

Of the literature summarized above, some focus on approach or technique (e.g. psychoanalysis, narrative therapy, etc.). All approaches were found to be generally effective, implying that it is perhaps the therapeutic relationship itself that is helpful, rather than any specific technique. Many of the summarized studies indeed looked more at general aspects of therapy and the quality of the relationship, as well as the impact of the therapist's own sensitivity to differences.

The research made it clear that therapist self-assessment did not give the full picture of the quality of therapy, and that LGBTQ+ clients seem to frequently experience difficulty as a result of prejudice, regardless of whether it is conscious or not. Though client assessment is also potentially susceptible to bias, a client is in a better position to evaluate whether or not they think that therapy improved their wellbeing, particularly when they belong to a marginalized group and dynamics of power and oppression enter into the discussion. Therefore, the present research set out to better understand what clients are experiencing in therapy. 


\section{ACTES DU SJPD-JPDS PROCEEDINGS, 2018, VOL. 2}

\section{Theoretical Framework}

In crafting this pilot study, the researcher drew two conclusions from the literature: 1) that the majority of research focused on the experiences of therapists, rather than on the clients; and 2) that many studies excluded certain queer identities without explicit justification (e.g., many excluded transgender participants, some excluded bisexual participants). These areas seemed to be gaps in the literature when it comes to the topic of therapy with LGBTQ+ clients. Therefore, this study was designed to centre the voices of LGBTQ+ clients to allow them to describe their own experiences in therapy.

The theoretical framework of this research was a combination of client-centered therapy and queer theory. Client-centered therapy, first pioneered by Carl Rogers, prioritizes the experiences of clients above the expertise of the therapist, whose primary role is to assist the client in gaining insight by listening empathically and non-judgmentally (Client-centered therapy, 2006). Queer theory is a school of thought meant to examine and challenge systems of power within society, including but not limited to heteronormativity and cisnormativity (Hodges, 2011). These approaches allowed the research to prioritize the clients' experience while also being critical of the systems of power that pervade both therapeutic relationships and society itself.

\section{Methodology}

To adhere to the client-centered approach, this was a qualitative study to allow participants to explain their own experiences. The researcher used a semi-structured interview to ensure that they addressed key topics, but to also allow for fluidity and spontaneity. This was a compromise between the researcher's agenda and the participants' agency.

All participants self-identified as members of the LGBTQ+ community. In order to be eligible, participants must have attended therapy where their gender and/or sexuality was discussed at some point. Participants were recruited through a public post on social media outreach for the Ottawa LGBTQ+ community asking for volunteers, and were compensated for their time with a non-alcoholic drink (e.g., a coffee). Six people responded, but two dropped out before they could be interviewed. All four remaining participants identified themselves as white, able-bodied, and educated; all four were between the ages of 18 and 25 . 


\section{ACTES DU SJPD-JPDS PROCEEDINGS, 2018, VOL. 2}

In accordance with the client-centered theoretical approach, the questions focused on drawing out the participants' own experiences. Participants were asked to identify what they found helpful or unhelpful in connecting with their therapist, and if they found any specific approaches to be helpful (e.g., narrative therapy, affirmative therapy). Finally, in an attempt to equalize the power discordance between therapist and client, particularly when minority identities are involved, participants were asked if they had any recommendations for therapists working with LGBTQ+ clients. Due to the semi-structured nature, every interview included spontaneous questions based on the responses of the participants.

\section{Ethical Considerations}

This research was conducted as part of the requirements for the class EDU 5190 Introduction to Research in Education, under the supervision of a university professor. Participants were presented with a consent form outlining the purpose of the study, the design of the questions, and the potential risks (e.g., potential emotional distress). The consent form was given to participants in advance, but also discussed in person to ensure understanding. After the interview, the participants were debriefed and invited to bring up any thoughts or feelings triggered by the discussion.

The interviews were conducted in the researcher's office with the door closed. Each interview took approximately one hour. Audio recordings of the interviews were stored on the researcher's computer under a locked file. Interviews were transcribed verbatim and then themes, similarities, and differences were identified. In accordance with the requirements of the class, and as described in the consent form, these recordings and any other identifying details about the participants were deleted at the conclusion of the class, in December 2017. There were no known breaches of privacy.

\section{Results}

The study was comprised of four individuals who self-identified as members of the LGBTQ+ community. Participant \#1 was a cisgender, bisexual woman. Participant \#2 was a cisgender, demisexual ${ }^{4}$ woman. Participant \#3 was a transgender man who defined his sexuality as "queer". Participant \#4 was a pansexual, nonbinary 5 person (i.e., "they/them"

\footnotetext{
4 "Demisexual" is a term that describes someone who cannot feel sexual attraction to another person until forming an emotional bond; considered to be under the asexual umbrella (Ginicola, Filmore, \& Smith, 2017).

5 "Nonbinary" is a term that describes someone whose gender is neither male nor female; usually spelled "nonbinary" but this participant indicated they spell it as one word.
} 


\section{ACTES DU SJPD-JPDS PROCEEDINGS, 2018, VOL. 2}

pronouns). Participants \#1 and \#4 described a mix of positive and negative experiences, both with therapy in general and discussing their identities. Participant \#1 reported that her experiences had been mostly positive, but that her therapist over-focused on her identity and coming out. Participant \#4 said that they were refused service by the first psychologist they contacted because the psychologist did not deal with "transgender issues". However, they were seeking therapy for anxiety, not for anything to do with their gender. They were later referred to a psychologist who dealt specifically with transgender clients, and while they were satisfied with their new psychologist, they expressed distress at the initial refusal.

Participant \#2 described having only negative experiences with therapy. She explained that while the relationship had always been problematic, attempting to discuss her sexuality had resulted in dismissal and rejection, which irrevocably damaged the relationship. Participant \#3 reported almost exclusively positive experiences in therapy; he and his therapist had a great relationship, and she was extremely supportive of his realization that he was transgender. He believed their good rapport was due in part to the fact that his therapist was herself gay, meaning that she already understood LGBTQ+ issues.

Something that all three participants with some negative experiences raised was the desire for therapists to have more knowledge about queer identities and issues facing the LGBTQ+ community, and/or for them to at least be more accepting of the client's experience of their identity. Participant \#4 explained that it was "exhausting" to constantly justify their identity to society at large, and that a truly therapeutic space would be one where they did not have to do this. The participants expressed that they realized queer terminology is constantly evolving, but an effort to stay on top of community terms and issues would be appreciated, and to take clients at their word.

When questioned about approach and technique, two of the four participants did not know what form of psychotherapy they had received. The other two participants had received cognitive-behavioural therapy, though neither had insight into whether this approach had been especially helpful to them. None of the participants identified any techniques that had been either helpful or harmful to them.

Participants \#1 and \#3 said that acceptance from the therapist strengthened the therapeutic relationship and helped them feel connected to their therapist. Participant \#4 felt connected to their second psychologist upon receiving affirmation, but the rejection from their first damaged their trust. The rejection that Participant \#2 received damaged the relationship beyond repair and their trust in the profession. 


\section{ACTES DU SJPD-JPDS PROCEEDINGS, 2018, VOL. 2}

\section{Discussion}

None of the participants felt their experience in therapy had been impacted by the therapeutic approach or techniques used. Therefore, no conclusions can be drawn from this study about whether or not any techniques are better suited to working with LGBTQ+ clients than others. Instead, the participants' experience of therapy was affected by their relationship with their therapist and how the therapist had responded to their identity.

Three out of four participants reported at least some level of dissatisfaction with the way in which their identity was handled by therapists, which is concerning. The only participant with exclusively positive experiences had a queer therapist, and while there are undoubtedly implications that could be drawn about the therapeutic power of being from the same marginalized group as one's client, this was not the focus of the present research. Non-queer therapists need to be able to connect with LGBTQ+ clients, and in this regard, the participants indicated disappointment.

As supported by much of the existing literature, the present study indicates that therapist competency with LGBTQ+ clients and issues could be improved (Cochran et al., 2003, O'Shaughnessy \& Spokane, 2013; Shelton \& Delgado-Romero, 2011). The three participants with mixed or negative experiences all experienced some form of microaggression, as described in research by Shelton and Delgado-Romero (2011) and Spengler et al. (2016). Participant \#2 had her identity dismissed by her therapist, and Participants \#1 and \#4 had their identities overemphasized by their therapists. Participant \#1's therapist overemphasized by pushing her to talk about it, while Participant \#4's therapist refused to treat them and pathologized their identity. In all three cases, their own experiences were invalidated and their needs were not met.

All four participants expressed a desire for therapists to have a better understanding of LGBTQ+ terminology and issues. They explained that they would be more comfortable with therapists who showed more knowledge and would, thus, find it easier to form a more trusting relationship. O'Shaughnessy and Spokane (2013), as well as Johnson and Federman (2014), showed that graduates are unprepared to counsel LGBTQ+ clients, a problem that could be countered in training. Alessi and colleagues $(2015 ; 2016)$ also support the need for more LGBTQ+ competency training in psychology and counselling programs. Resources such as Dworkin and Pope (2015) or Ginicola et al. (2017) and mandatory courses on multicultural counselling could be used to enhance therapist competency. A shift needs to be made in the overall institution of psychology towards understanding and catering to diverse 


\section{ACTES DU SJPD-JPDS PROCEEDINGS, 2018, VOL. 2}

populations, and some of this could also come from supervisors once in the field, as shown in Chui et al.'s (2017) research.

The major limitation to the present research is that it was not sufficiently intersectional, and therefore missing additional complexity in therapeutic relationships. None of the participants were double minorities, who, as discussed in the research by Hicks (2010), face different struggles than those who have only a marginalized sexuality or gender. Intersectionality is an important part of working with LGBTQ+ clients (Addison \& Coolhart, 2015), and, therefore, future research should seek to gather information from queer people of colour, disabled queer people, etc. Furthermore, there may have been selection bias in those who agreed to participate. For example, those who agreed to participate may have been more inclined to do so because they had negative experiences they wanted to share.

\section{Conclusion}

The objective of this study was to determine what kinds of experiences LGBTQ+ clients were having in therapy, and what was contributing to those experiences. Three out of four participants expressed some level of dissatisfaction, which is a concerning statistic. These participants experienced that theoretical approach and technique had less of an impact on their outcome than the relationship they had with their therapist, which was impacted by conscious or unconscious bias.

Because the dissatisfaction revolved around how their sexuality or gender was handled, the results imply that LGBTQ+ clients are at a disadvantage when it comes to accessing mental health services, which is backed up by previous research. These experiences may result in worse mental health outcomes and may drive LGBTQ+ people away from seeking help. Therefore, therapists must work even harder to prevent these disconnects from happening.

Though the present research is only a pilot study, and future more intersectional research should be conducted, the results indicate that therapists should trust in their clients' experiences and actively work to learn more about the LGBTQ+ community. Potentially, this problem could be addressed in their education and training, with more emphasis being placed on multicultural counselling and connecting with clients who are members of different minority groups than the therapist. 


\section{ACTES DU SJPD-JPDS PROCEEDINGS, 2018, VOL. 2}

\section{References}

Addison, S. M., \& Coolhart, D. (2015). Expanding the therapy paradigm with queer couples: A relational intersectional lens. Family Process, 54(3), 435-453.

Alessi, E. J., Dillon, F. R., \& Kim, H. M. (2015). Determinants of lesbian and gay affirmative practice among heterosexual therapists. Psychotherapy, 52(3), 298-307.

Alessi, E. J., Dillon, F. R., \& Kim, H. M. (2016). Therapist correlates of attitudes toward sexual minority individuals, affirmative counselling self-efficacy, and beliefs about affirmative practice. Psychotherapy Research, 26(4), 446-458.

Bidell, M. P. (2017). The lesbian, gay, bisexual, and transgender development of clinical skills scale (LGBT-DOCSS): Establishing a new interdisciplinary self-assessment for health providers. Journal of Homosexuality, 64(10), 1432-1460.

Bidell, M., \& Whitman, J. (2013). A review of lesbian, gay, and bisexual affirmative counselling assessments. Counseling Outcome Research and Evaluation, 4(2), 112-126.

Chui, H., McGann, K. J., Ziemer, K. S., Hoffman, M.A., \& Stahl, J. (2017). Trainees' use of supervision for therapy with sexual minority clients: A qualitative study. Journal of Counseling Psychology. Advance online publication, 1-15. Retrieved from http://resolver.scholarsportal.info/resolve/00220167/v65i0001/36 tuosftsmc $\underline{\mathrm{aqs}}$

Client-centered therapy. (2006). Cover story. Harvard Mental Health Letter, 22(7), 1-3.

Cochran, S. D., Greer Sullivan, J., \& Mays, V. M. (2003). Prevalence of mental disorders, psychological distress, and mental health services use among lesbian, gay, and bisexual adults in the united states. Journal of Consulting and Clinical Psychology, 71(1), 53-61.

American Psychiatric Association. (2000). Diagnostic and statistical manual of mental disorders. ( $4^{\text {th }}$ ed., Text Revision). Washington, DC: American Psychiatric Publishing.

American Psychiatric Association. (2013). Diagnostic and statistical manual of mental disorders. (5th ed.). Arlington, VA: American Psychiatric Publishing. 


\section{ACTES DU SJPD-JPDS PROCEEDINGS, 2018, VOL. 2}

Diamond, G. M., \& Shpigel, M. S. (2014). Attachment-based family therapy for lesbian and gay young adults and their persistently nonaccepting parents. Professional Psychology: Research and Practice, 45(4), 258-268.

Dworkin, S. H. \& Pope, M. (Eds.). (2015). Casebook for counselling: Lesbian, gay, bisexual, transgender persons and their families. Alexandria, VA: American Counseling Association.

Ebersole, R. C., Dillon, F. R., \& Eklund, A. C. (2018). Mental Health Clinicians' Perceived Competence for Affirmative Practice with Bisexual Clients in Comparison to Lesbian and Gay Clients. Journal of Bisexuality, ISSUE AND VOLUME, 1-18.

Ginicola, M. M., Smith, C., \& Filmore, J. M. (Eds.) (2017). Affirmative, strengths-based counselling with LGBTQI+ people. Alexandria, VA: American Counseling Association,

Hicks, C. (2010). Counselling psychology contributions to understanding sexuality. In M. Milton (Ed.), Therapy and beyond: Counselling psychology contributions to therapeutic and social issues (pp. 243-258). Chichester, UK: John Wiley \& Sons, Ltd..

Hodges, I. (2011). Queering psychoanalysis: Power, self and identity in psychoanalytic therapy with sexual minority clients. Psychology \& Sexuality, 2(1), 29-44.

Johnson, L., \& Federman, E. J. (2014). Training, experience, and attitudes of VA psychologists regarding LGBT issues: Relation to practice and competence. Psychology of Sexual Orientation and Gender Diversity, 1(1), 10-18.

McDowell, T., Emerick, P., \& Garcia, M. (2014). Queering couple and family therapy education. Journal of Feminist Family Therapy, 26(2), 99-112.

O'Shaughnessy, T., \& Speir, Z. (2018). The state of LGBQ affirmative therapy clinical research: A mixed-methods systematic synthesis. Psychology of Sexual Orientation and Gender Diversity, 5(1), 82-98.

O’Shaughnessy, T., \& Spokane, A. (2013). Lesbian and gay affirmative therapy competency, self-efficacy, and personality in psychology trainees. The Counseling Psychologist, 41(6), 825-856. 


\section{ACTES DU SJPD-JPDS PROCEEDINGS, 2018, VOL. 2}

Shelton, K., \& Delgado-Romero, E. A. (2011). Sexual orientation microaggressions: The experience of lesbian, gay, bisexual, and queer clients in psychotherapy.Journal of Counseling Psychology, 58(2), 210-221.

Sherry, A., Whilde, M. R., \& Patton, J. (2005). Gay, lesbian, and bisexual training competencies in American Psychological Association accredited graduate programs. Psychotherapy: Theory, Research, Practice, Training, 42(1), 116-120.

Spengler, E. S., Miller, D. J., Spengler, P. M. (2016). Microaggressions: Clinical errors with sexual minority clients. Psychotherapy, 53(3), 360-366.

Steelman, S. M. (2016). Externalizing identities: An integration of narrative therapy and queer theory. Journal of Family Psychotherapy, 27 (1), 79-84. 